\title{
O produtor cultural e a formalização de sua atividade
}

\author{
El gestor cultural y la formalización de su actividad
}

The cultural producer and the formalization of its activity

\author{
Sandra Helena Pedroso ${ }^{1}$
}

\author{
Palavras chave: \\ Produtor cultural \\ MEl \\ EIRELI \\ Profissão
}

\section{Resumo:}

Funções do produtor cultural tomando por base a formalização da atividade frente ao Ministério do Trabalho e ao mercado cultural. Novos caminhos propiciados pela formalização da profissão, a formação profissional e o conhecimento diferenciado. 


\section{Resumen:}

Funciones del gestor cultural, con un análisis central en la formalización de la actividad frente al Ministerio de Trabajo y al mercado cultural. Nuevos caminos propiciados por la formalización de la profesión, la formación profesional y el conocimiento diferenciado.

Palabras clave:

Gestor cultural

MEI

EIRELI

Profesión

\section{Keywords:}

Cultural producer

MEI

EIRELI

Profession

\section{Abstract:}

Cultural producer functions based on the formalization of the activity at Ministry of Labour's rule and the cultural market. New paths provided formalisation of the profession, professional training and differentiated knowledge. 


\section{A sociedade envelhecida, diante da reprodução social e a ação contra hegemônica}

\section{Introdução}

Este artigo tem por objetivo conceituar Produtor Cultural frente ao reconhecimento da profissão em 2013 pelo Ministério do Trabalho, e comentar sua regulamentação, que, tendo ocorrido em 1978, até hoje não sofreu revisão frente aos novos arranjos produtivos, às novas formas de contratação e às novas profissões derivadas da antiga.

Para isso será utilizada como metodologia a revisão bibliográfica de estudiosos sobre o assunto e as legislações vigentes.

\section{Desenvolvimento}

O profissional produtor cultural desenvolve muitas atividades e, por isso, Ihe cabem diversas definições. Este artigo se inicia com algumas conceituações de renomados professores e pesquisadores que possam conduzir ao entendimento da regulamentação da profissão.

Marcondes Neto (2006) define o produtor cultural como "a embreagem entre o criador primeiro e o público alvo". Para Linda Rubim (2005) o produtor cultural é o profissional que idealiza, cria, planeja, controla, executa e supervisiona, e que, em alguns casos, também assume a função de captador de recursos.

Teixeira Coelho (2004) define esse profissional como Agente cultural: agente cultural e intermediário cultural. "É aquele que se envolve com a administração das artes e da cultura criando as condições para que outros criem ou inventem seus próprios fins culturais. Atua mais junto ao público do que próximo ao produtor cultural. Ou seja, faz a ponte entre a produção cultural e seus possíveis públicos". Esta definição está muito relacionada aos anos 80 e 90 como apontam alguns pesquisadores.

O Guia do Estudante define produtor cultural como aquele que cria e organiza projetos artísticos e culturais espetáculos de teatro, dança e música, produções televisivas, festivais, mostras e eventos. Cuida de todas as etapas do projeto, da captação de recursos à sua realização final. Pode trabalhar com artistas ou com organizações e empresas voltadas para a área cultural. Como produtor executivo, faz o orçamento do projeto, define cronogramas e busca recursos para a montagem da obra.

O Info Escola define como produtor cultural da comunidade aquele que apresenta performance profissional, semiprofissional ou amadora na esfera da cultura, ou seja, artistas, artesãos, promotores culturais etc.

Roberto Corrêa Cobas Costas entende a produção cultural como uma área de atuação muito ampla, cabendo ao profissional as seguintes funções:

- criar e organizar projetos e produtos artístico-culturais;

- estabelecer metas e estratégias;

- planejar, organizar e divulgar projetos e produtos culturais de toda natureza;

- promover a integração entre criação artística e gerência administrativa na produção de espetáculos, produtos audiovisuais, obras literárias;

- atuar na curadoria e organização de mostras, exposições e festivais em diversas áreas artísticas;

- trabalhar em setores de marketing 
cultural, desenvolvendo estratégias de Investimento em projetos culturais;

- exercer a gerência cultural e operacional em instituições públicas e privadas, atuando em centros culturais, galerias de arte, museus, bibliotecas, teatros, cinemas;

- compor equipes governamentais de gestão cultural em níveis municipal, estadual e federal, auxiliando na definição de políticas públicas para a cultura;

- contribuir nas ações de preservação e revitalização do patrimônio cultural;

- atuar no ensino, pesquisa e extensão no magistério superior, nas áreas de produção cultural e afins.

Para Romulo Avelar (2008) é um agente que deve ocupar a posição central nesse processo, desempenhando o papel de interface entre os profissionais da cultura e os demais segmentos. Atua como "tradutor" das diferentes linguagens artísticas.

Segundo André Midani, executivo da indústria fonográfica, "Tem vários tipos de produtores culturais. O produtor cultural que é a pessoa que vai buscar fundos para investir em um determinado artista ou num grupo de artistas, haja vista a Lei Rouanet, por exemplo. E tem outro tipo de produtor cultural. Da música é a pessoa que se encarrega de ser o companheiro do artista e que ajuda o artista a conceituar sua música. Este é um produtor cultural também. Este não vai atrás do dinheiro, este vai atrás do talento."

O Ministério do Trabalho e Emprego - MTE define as funções dos produtores culturais: "Implementam projetos de produção de espetáculos artísticos e culturais (teatro, dança, ópera, exposições e outros), audiovisuais (cinema, vídeo, televisão, rádio e produção musical) e multimídia. Para tanto criam propostas, realizam a pré-produção e finalização dos projetos, gerindo os recursos financeiros disponíveis para o mesmo". Esta definição foi adotada a partir da reflexão de um grupo de especialistas convidados pelo MTE para rever o Código Brasileiro de Ocupação - CBO e no qual foi incluída a profissão de Produtor Cultural.

O CBO, de acordo com a Portaria $n^{\circ}$ 397, de 09 de outubro de 2002 do MTE é importante para:

Art. $2^{\circ}$ - Determinar que os títulos e códigos constantes na Classificação Brasileira de Ocupações - CBO/2002, sejam adotados;

I. nas atividades de registro, inscrição, colocação e outras desenvolvidas pelo Sistema Nacional de Emprego (SINE);

II. na Relação anual de Informações Sociais - (RAIS);

III. nas relações dos empregados admitidos e desligados - CAGED, de que trata a Lei $\mathrm{N}^{\circ} 4923$, de 23 de dezembro de 1965;

IV. na autorização de trabalho para mão-de-obra estrangeira;

V. no preenchimento do comunicado de dispensa para requerimento do benefício Seguro Desemprego (CD);

VI. no preenchimento da Carteira de Trabalho e Previdência Social CTPS no campo relativo ao contrato de trabalho;

VII. nas atividades e programas do Ministério do Trabalho e Emprego, quando for o caso;

Art. $4^{\circ}$ - Os efeitos de uniformização pretendida pela Classificação Brasileira de Ocupações (CBO) são de ordem administrativa e não se estendem às relações de emprego, não havendo obrigações decorrentes da mudança da nomenclatura do cargo exercido pelo empregado. 
Além da definição, o MTE também definiu qual a formação, experiência e condições gerais para o exercício da profissão de Produtor Cultural:

\section{Formação e experiência}

Essas ocupações não demandam nível de escolaridade determinado para seu desempenho, sendo possível que sua aprendizagem ocorra na prática. Seguindo a tendência de profissionalização que vem ocorrendo na área das artes, contudo, pode-se afirmar que, cada vez mais, será desejável que os profissionais apresentem escolaridade de nível superior.

\section{Condições gerais de exercício}

Trabalham principalmente em atividades culturais, recreativas, desportivas, em empresas públicas ou privadas, como empregados ou prestadores de serviços. As habilidades de pesquisa, organização, supervisão e de relacionamento interpessoal são importantes para o exercício das suas atividades, as quais se desenvolvem predominantemente em equipes e em horários irregulares.

Somente a partir desse estudo se incluiu no CBO a profissão de Produtor Cultural, optando-se por colocar a denominação na categoria já existente de Produção Artística. Por isto se utilizou do mesmo formato da família, sendo o código raiz, ocupação a profissão, e o sinônimo o que deriva da ocupação. Desta forma, os profissionais de Produção Cultural, inclusive os portadores de diploma, ficaram incluídos na seguinte estrutura:

2 PROFISSIONAIS DAS CIÊNCIAS E DAS ARTES

2621 Produtores artísticos e culturais
- Família

2621-05 Produtor cultural Ocupação

2621 -05 Empresário de espetáculo, tecnólogo em produção cultural

2621-10 Produtor cinematográfico Ocupação

2621-10 Produtor de imagem (cinema) Sinônimo

2621-10 Produtor de som (cinema) Sinônimo

2621-15 Produtor de rádio Ocupação 2621-15 Produtor de som (rádio) Sinônimo

2621-20 Produtor de teatro Ocupação 2621-20 Produtor de som (teatro) Sinônimo

2621-25 Produtor de televisão Ocupação

2621-25 Produtor de imagem (televisão) Sinônimo

2621-25 Produtor de programa Sinônimo

2621-25 Produtor de som (televisão) Sinônimo

Está prevista na Lei $\mathrm{n}^{\circ} 6.533$, de 24 de maio de 1978, e foi regulamentada pelo Decreto $\mathrm{n}^{\circ} 82.385,05$ de outubro de 1978, que criou e regulamentou as profissões de artista e de técnico em espetáculos de diversões. Portanto é esta legislação que caracteriza os técnicos em espetáculos de diversões como "o profissional que, mesmo em caráter auxiliar, participa, individualmente ou em grupo, de atividade profissional ligada diretamente à elaboração, registro, apresentação ou conservação de programas, espetáculos e produções".

O Decreto $n^{\circ} 82.385 / 1978$, inclusive nos seus artigos $7^{\circ}, 8^{\circ}$ e $9^{\circ}$, define como podem os artistas e técnicos atuar no mercado e obter o registro profissional:

Art. 7o - O exercício das profissões de Artista e de Técnico em Espetáculos de Diversões requer prévio registro na 
Delegacia Regional do Trabalho do Ministério do Trabalho, o qual terá validade em todo o território nacional.

Art. 8o - Para registro do artista ou do Técnico em Espetáculos de Diversões, no Ministério do Trabalho, é necessária a apresentação de:

I - diploma de curso superior de Diretor de Teatro, Coreógrafo, Professor de Arte dramática ou outros cursos semelhantes, reconhecidos na forma da Lei; ou

II - diploma ou certificado correspondente às habilitações profissionais de 20 grau de Ator, Contrarregra, Cenógrafo, Sonoplasta, ou outros reconhecidos na forma da Lei; ou

III - atestado de capacitação profissional fornecido pelo sindicato representativo das categorias profissionais e, subsidiariamente, pela federação respectiva.

Art. 9o - O atestado mencionado no item III do artigo anterior deverá ser requerido pelo interessado, mediante preenchimento de formulário próprio, fornecido pela entidade sindical, e instruído com documentos ou indicações que comprovem sua capacitação profissional.

Dentro do Quadro Anexo ao Decreto no 82.385 , de 05 de outubro de 1978 - Títulos e Descrições das Funções em que se desdobram as atividades de Artistas e Técnicos em Espetáculos de Diversões - não existe a categoria específica de Produtor e sim o de Diretor de Produção, que deverá se encarregar da produção do espetáculo junto à equipe técnica e artística, analisar e planejar as necessidades de montagem e controlar o andamento da produção, dando cumprimento a prazos e tarefas. Por quê? Porque a legislação assume que o produtor é o contratante de uma produção, inclusive na definição da função de Di- retor quando indica: "na relação com o Produtor fica preservada a sua autonomia quanto à criação; define com o Produtor a equipe técnica e artística".

Dito isso passamos a outro questionamento, o porquê de não ser possível conseguir a formalização da atividade através do registro de Micro Empreendedor Individual - MEI, figura jurídica definida pela Lei Complementar $n^{\circ} 128 / 2008$, para que o trabalhador informal possa se tornar legalizado e usufruir de benefícios, como previdência e acesso a compras públicas.

O MEI é a pessoa que trabalha por conta própria e que se legaliza como empresário. Porém com a seguinte condição: podem se legalizar aqueles que exercem atividades de comércio, indústria e serviços de natureza não intelectual/sem regulamentação legal, a saber, pessoas que exerçam a função como ambulante, camelô, artesão, costureira, lava-jato, reparação, encanadores, borracheiros etc. Ou seja, pela simples razão do Produtor Cultural ter regulamentação legal e ser de natureza intelectual, fica impedido de ser um MEl ou El.

Vale ressaltar também que, nos termos do parágrafo único do art. 966 do Código Civil, não são considerados empresários aqueles que exercem profissão de natureza intelectual (contadores, engenheiros, médicos, arquitetos, advogados etc.), científica (pesquisadores em geral), literária ou artística (músicos, atores, modelos etc.), ainda que se valham de auxiliares ou colaboradores, exceto se o exercício destas atividades constituir elemento de empresa - ou seja, se for perdida a pessoalidade do empreendedor no exercício das atividades, que passarão a ser exercidas pelos empregados, enquanto que o empreendedor passará apenas a administrá-lo, articulando os fatores de produção. 
Uma solução é constituir uma ElRELI, ou seja, uma Empresa Individual de Responsabilidade Limitada que tem as mesmas características de uma empresa Limitada, mas com a vantagem de não ter necessidade de um sócio e poderá ser optante do sistema de tributação do Simples Nacional, pela qual recolherá impostos de forma unificada, ou seja, em uma única guia chamada de DAS, com alíquota em torno de $4,5 \%$, onde estão incluídos os seguintes impostos: IRPJ, Patronal do INSS, IPI, CSLL, PIS/PASEP, COFINS, ISS e ICMS. O IPTU não se encontra dentre esses impostos por se referir a imóvel e não à atividade profissional. Ressalta-se que as empresas optantes pelo Sim- ples Nacional "não poderão apropriar ou transferir créditos relativos a impostos ou contribuições abrangidos por esse regime, nem poderão utilizar ou destinar qualquer valor a título de incentivo fiscal", de acordo com o que informa o sítio eletrônico da Receita Federal. Tendo em vista a nossa legislação, compreendo que algumas vezes fica complicado entender a questão. Por exemplo, as funções de Fotógrafo e Maquiador, que estão numa mesma categoria, podem ser El porque eles podem prestar serviços em outras áreas que não a cultural.

De todo jeito, segue abaixo um quadro demonstrativo do número de empresas da área cultural que são $\mathrm{El}$ :

\begin{tabular}{|c|c|c|}
\hline CNAE & DESCRIÇÃO DO CNAE² & $\begin{array}{c}\text { Total de } \\
\text { empresas no } \\
\text { SIMEI }^{3} \\
\end{array}$ \\
\hline 9001901 & Produção Teatral & 2.205 \\
\hline 9001902 & Produção Musical & 10.864 \\
\hline 9001903 & Produção de Espetáculos de Dança & 3 \\
\hline 9001904 & $\begin{array}{l}\text { Produção de Espetáculos Circenses, de Marionetes e } \\
\text { Similares }\end{array}$ & 2 \\
\hline 9001905 & $\begin{array}{l}\text { Produção de Espetáculos de Rodeios, Vaquejadas e } \\
\text { Similares }\end{array}$ & 3 \\
\hline 9001906 & Atividades de Sonorização e de lluminação & 4.958 \\
\hline 9001999 & $\begin{array}{l}\text { Artes Cênicas, Espetáculos e Atividades } \\
\text { Complementares não Especificadas Anteriormente }\end{array}$ & 12 \\
\hline 9002701 & $\begin{array}{l}\text { Atividades de Artistas Plásticos; Atividades Literárias; } \\
\text { Serviços de Cartunista; Criador de Desenho Animado; } \\
\text { Gestão de Direitos Autorais de Obras de Arte; Escritor; } \\
\text { Escultor; Jornalista Independente; Pintor Artístico; } \\
\text { Serviços de Pintura de Artesanato; }\end{array}$ & 16 \\
\hline 9002702 & $\begin{array}{l}\text { Restauração de Objetos de Arte; Serviços de } \\
\text { Restauração de Esculturas, Restauração de Obras de } \\
\text { Arte; Restauração de Obras e Imagens Sacras e } \\
\text { Restauração de Quadros. }\end{array}$ & 361 \\
\hline 9101500 & $\begin{array}{l}\text { Atividade de Arquivo; Biblioteca; Documentação e } \\
\text { Pesquisa Bibliográfica; Gestão de Arquivos Públicos; } \\
\text { Gestão de Bibliotecas Públicas; Salas de Leitura. }\end{array}$ & 1 \\
\hline
\end{tabular}


As definições do TEM e da legislação vão ao encontro do questionamento da Profa Maria Helena Melo da Cunha (2007) que pergunta "O que difere um produtor de um gestor cultural? Essa diferenciação é uma ação ou o reflexo da realidade vivida por esses profissionais que, diante da complexidade das relações de trabalho, deparam com esse questionamento, no qual o produtor tem sido colocado como um profissional mais executivo e o gestor, no âmbito das ações mais estratégicas."

Yakoff Sarcovas, Presidente das empresas Articultura e Significa, entende o produtor cultural como um Produtor Gestor:

O que eu pude depreender desta minha passagem pela produção cultural do país, essa área que eu chamo de área cultural não industrial (as companhias de teatro, de dança, mesmo os museus) é que essas são áreas em que há muita competência artística e baixa competência de gestão, de administração. [...] Hoje, felizmente, você tem um processo de profissionalização não artística ocorrendo na área cultural brasileira. Isto é importantíssimo porque o gestor cultural tem capacidade de ampliar a efetividade da ação cultural.

Rômulo Avelar faz a distinção entre o Produtor Cultural e o Gestor Cultural por este último poder estar presente também em outros contextos, como contratado de uma empresa para o trato das questões relativas ao patrocínio à cultura, como agente vinculado a órgão público ou como administrador de um espaço cultural privado, público ou pertencente à organização não governamental. Esse conceito vem ao encontro de Yael Steiner do Centro de Cultura Judaica que diz que o produtor cultural traz o empreendedorismo na veia, pois cultura requer muita criatividade.

Como podemos verificar pelas definições apresentadas, o Produtor Cultural tem diversas funções a desempenhar num projeto cultural, num espaço cultural ou na gestão de um artista.

Creio que podemos dizer, então, que o produtor cultural e o gestor exercem funções correlatas, complementares; são empreendedores, criativos e tanto podem ser artistas como administradores ou, ainda, realizar as duas atividades.

Por esta razão é que, para atender esse mercado em expansão e à demanda, existem diversas universidades no Brasil com graduação em Produção Cultural, conforme levantamento dos Profs. Kátia De Marco e Luiz Augusto Rodrigues: Instituto Universitário de Pesquisas do Rio de Janeiro/Universidade Cândido Mendes - IUPERJ/UCAM, Universidade Federal da Bahia - UFBA, Universidade Federal Fluminense - UFF e algumas das unidades dos Institutos Federais de Educação, Ciência e Tecnologia. No Rio de Janeiro temos o IFRJ e a Universidade dos Pampas - UNIPAMPA, ou seja, temos 5 cursos de Produção Cultural a nível de bacharelado, 9 com habilitação em Produção Cultural e 41 que formam tecnólogos. Além de diversos cursos livres de boa qualidade, são 30 de pós-graduação, 9 de mestrado acadêmico, 4 de mestrado profissional e 2 de doutorado que possibilitam a profissionalização na carreira bem como proporcionam novos olhares e formas de exercer a profissão.

\section{Conclusão}

Pode-se dizer que, com a profissionalização e a regulamentação da profissão, será possível a mudança de paradigma na contratação de profissionais. Porém não podemos descartar a possibilidade de uma saída não tão rápida para modificar a situação. Entendo que a discussão e a união de forças pelo bem comum são o pontapé inicial para isso. Principalmente para que possamos obter o registro pro- 
fissional sem ter que depender dos sindicatos da categoria atualmente existentes, como determina a legislação.

O próximo passo será solicitar, através do Serviço de Apoio às Micro e pequenas Empresas - SEBRAE e do Sindicato dos Escritórios de Contabilidade - SESCON, que participam do Comitê Gestor do Empreendedor, que a profissão de Produtor Cultural, juntamente com as derivações, por sua peculiaridade, sejam incluídas no rol de atividades que possam ser formalizadas através do El, da mesma forma que os produtores culturais fizeram em 2008 para que fizessem parte do Anexo $\mathrm{V}$ do Simples Nacional, já mencionado anteriormente.

Tomando por base as recentes conquistas dos músicos no Congresso, sugiro ampliar a discussão sobre o elevado custo da tributação no Brasil, principalmente para as empresas de produção cultural e seus trabalhadores, em função da sazonalidade e da peculiaridade das profissões artísticas, e da falta de visibilidade da boa aplicabilidade destes recursos.

\section{Bibliografia}

AVELAR, Rômulo. O avesso da cena: notas sobre produção e gestão cultural, Belo Horizonte: DUO Editorial, 2008.

CARTILHA DO EIRELI - SESCON Distrito Federal (Sindicato das Empresas de Serviços Contábeis e das Empresas de Assessoramento, Perícias, Informações e Pesquisas do Distrito Federal). 2012.

COELHO, Teixeira. Dicionário crítico de política cultural. São Paulo: Editora lluminuras, 2004.

COSTAS, Roberto Corrêa Cobas. http://www.lenderbook.com/cultural/index.asp. Acessado em 29/09/2013.
CUNHA, Maria Helena Melo da. Gestão Cultural: profissão em formação, Belo Horizonte: Duo Editorial, 2007.

GUIA DO ESTUDANTE. http://guiadoestudante.abril. com.br/profissoes/comunicacao-informacao/producao-cultural-688147.shtml. Acessado em 29/09/2013.

INFOESCOLA. http://www.infoescola.com/profissoes/agente-cultural/asp. Acessado em 29/09/2013.

MACHADO NETO, Manuel Marcondes. Marketing para as artes: a evolução do conceito de marketing cultural e a importância deste campo de atuação para o profissional de Relações públicas. Artigo publicado na Organicom em 2006.

MINISTÉRIO DO TRABALHO E EMPREGO. www. mtecbo.gov.br/cbosite/pages/home.jsf. Acessado em 27/02/2013.

OLIVIERE, Cristiane ; NATALE, Edson. Guia brasileiro de produção cultural: 2010-2011.São Paulo: SESC SP, 2010.

PORTALDO EMPREENDEDOR. www.portaldoempreendedor.gov.br/legislacao. Acessado em 18/04/2013.

PRODUÇÃO CULTURAL. www.producaocultural.org.br/no-blog/o-que-e-um-produtor-cultural/. Acessado em 18/04/2013.

RUBIM, Linda (org.). Organização e produção da cultura. Salvador: EDUFBA, 2005
1 Doutoranda em Ciências Políticas no IUPERJ/UCAM. Mestre em Sistema de Gestão de Projetos Sociais pela UFF. Professora do Bacharelado de Ciências Sociais com ênfase em Produção e Política Cultural do IUPERJ/ UCAM e da Pós-graduação em Produção Cultural da UCAM/ABGC. Membro do Comitê Setorial da CCPC do ISS/RJ. Contato: sandrahpedroso@gmail.com

2 CNAE - Código nacional de atividade econômica.

3 SIMEI - O El (Empreendedor individual) Sistema de Recolhimento em Valores Fixos Mensais dos Tributos Abrangidos pelo Simples Nacional (é a forma de recoIhimento simplificada, onde os tributos do IR, ISS e, em alguns casos, o INSS está incluído). 